\title{
TINJAUAN PERFORMANSI BUBUT DOALL LT13 TERHADAP PENYIMPANGAN KEBULATAN BENDA KERJA
}

\author{
Ariyanto $^{1}$, Husman ${ }^{2}$, Yuli Dharta ${ }^{3}$ \\ ${ }^{1,3,}$ Teknik Mesin, Polman Babel, Kawasan Industri Air Kantung, Bangka, 33211 \\ ${ }^{2}$ Teknik Elektronika, Polman Babel, Kawasan Industri Air Kantung, Bangka, 33211 \\ Tel: 0717-93586, Fax: 0717-93585, Ariyanto2176@gmail.com
}

\begin{abstract}
The industry manufacture with high quality and able to pruduce the workpicece with high quality In industry manufacture are very necessary. The use of high quality machines should be supported by the ability to operate and the ability to perform maintenance, this ability is useful to maintain the condition of the machine in order to produce good quality workpieces. Politeknik Manufaktur Negeri Bangka Belitung has several high quality machine tools, one type of machine tools usually use is lathe machine doall LT13 with total have six units. this machine Used to support education and to produce spare parts. Doall LT13 lathes have been used for 22 years, during that period there may be deviation of machine geometry, deviations that occur can lead to decreased quality of the resulting workpiece. This study aims to determine the feasibility of the machine by measuring the roundness of the spicemen of the process of turning, the roundness of the specimen is analyzed by using the minimum circle method. From the roundness testing performed on the doall It 13 the result that can be achieved as follows $0,082 \mathrm{~mm}$ at lathe number $8,0,073 \mathrm{~mm}$ at lathe number $5,0,057 \mathrm{~mm}$ at lathe number 7, 0,051 $\mathrm{mm}$ at lathe number 2,0,048 $\mathrm{mm}$ at lathe number 6 and 0,046 $\mathrm{mm}$ at lathe number 3 .
\end{abstract}

Keywords: Turning Machine, minimum area circle, out of roundness

\begin{abstract}
Abstrak
Mesin mesin manufaktur dengan kualitas yang tinggi dan mampu menghasilkan benda kerja dengan kualitas yang baik sangat diperlukan oleh industri manufaktur. Penggunaan mesin dengan kualitas tinggi harus didukung oleh kemampuan untuk mengoperasikan dan kemampuan untuk melakukan perawatan, kemampuan ini berguna untuk mempertahankan kondisi mesin agar dapat menghasilkan kualitas benda yang baik. Penggunaan mesin perkakas dengan kualitas tinggi juga digunakan di Politeknik Manufaktur Negeri Bangka Belitung, salah satu jenis mesin yang digunakan tersebut adalah mesin bubut doall LT13 dengan jumlah sebanyak enam unit, Penggunaan mesin ini untuk mendukung keperluan penyelenggaraan pendidikan dan untuk menghasilkan suku cadang. Mesin bubut Doall LT13 sudah digunakan selama 22 tahun, selama periode tersebut kemungkinan terjadi penyimpangan geometri mesin, penyimpangan yang terjadi dapat mengakibatkan penurunan kualitas benda kerja yang dihasilkan. Penelitian ini bertujuan untuk mengetahui kelayakan mesin dengan cara mengukur kebulatan benda uji hasil proses pembubutan, kebulatan benda uji dianalisa dengan menggunakan metoda lingkaran daerah minimum. Dari pengujian kebulatan yang telah dilakukan penyimpangan kebulatan yang mampu dicapai oleh mesin bubut doall It 13 sebagai berikut 0,082 $\mathrm{mm}$ pada mesin bubut nomor $8.0,073 \mathrm{~mm}$ pada mesin bubut nomor $5,0,057 \mathrm{~mm}$ pada mesin bubut nomor 7, 0,051 $\mathrm{mm}$ pada mesin bubut nomor 2, 0,048 $\mathrm{mm}$ pada mesin bubut nomor 6 dan 0,046 mm pada mesin bubut nomor 3 .
\end{abstract}

Kata Kunci: Mesin Bubut, Lingkaran daerah minimum, ketidakbulatan

1. PENDAHULUAN

Mesin bubut DoAll Lt13 yang digunakan di Politeknik Manufaktur Negeri Bangka Belitung sudah mencapai usia 22 tahun. Melihat usia pakai yang sudah sangat lama pada mesin tersebut dapat berdampak terhadap kemampuan mesin untuk menghasilkan suatu penyimpangan bentuk geometrik produk. penyimpangan geometrik produk selain disebabkan oleh mesin perkakas juga dapat dipengaruhi

Tinjauan Performansi Bubut DoALL LT13 Terhadap Penyimpangan Kebulatan Benda Kerja (Ariyanto) 
oelh beberapa faktor lain yaitu jenis dan kondisi alat potong, tool holder, kecepatan potong, feed dan chipsection, material yang dipotong, bentuk ukuran dan kekakuan benda kerja, peralatan pencekaman, keterampilan operator[1].

Salah satu pengujian yang dilakukan untuk mengetahui kemampuan mesin perkakas yaitu pengujian kebulatan, pengujian ini melihat kemampuan mesin untuk menghasilkan suatu produk. Pengujian kebulatan sudah diterapkan pada produk benda hasil gerinda Special Atachment [2]. Special Atachmnet yang digunakan digabung dengan dua jenis mesin bubut, dari hasil penelitian tersebut diketahui bahwa mesin Special Atachmnent tersebut mampu menghasilkan benda kerja dengan nilai ketidakbulatan pada mesin 1 minimal sebesar $0,0079 \mathrm{~mm}$ dan maksimal 0,014 $\mathrm{mm}$, pada mesin 2 ketidakbulatan minimal 0,0105 $\mathrm{mm}$ dan maksimal 0,0376 mm. Untuk mengetahui kemampuan mesin Doall Lt 13 membubut benda kerja maka dilakukan pengujian kebulatan hasil pembubutan, dengan membubut benda uji hingga mencapai ukuran yang diinginkan kemudian dilakukan analisis menggunakan metoda lingkaran daerah minimum. Dari hasil pengukuran kebulatan hasil pemotongan akan diketahui berapa besar nilai ketidakbulatan yang dicapai oleh mesin bubut Doall LT13.

Penelitian bertujuan untuk mengetahui penyimpangan kebulatan benda kerja yang terjadi setelah digunakan untuk proses belajar mengajar dan pembuatan suku cadang selama 22 tahun, serta mengetahui kelayakan mesin bubut jika digunakan untuk memproses benda kerja dengan toleransi ukuran tertentu

Kebulatan adalah suatu harga yang dapat dihitung berdasarkan profil kebulatan relatif terhadap lingkaran referensinya. Untuk menganalisa kebulatan dengan menggunakan lingkaran referensi menggunakan 4 cara yaitu lingkaran luar minimum [3]. lingkaran dalam maksimum,lingkaran daerah minimum dan lingkaran kuadrat terkecil lihat pada Gambar 1. Pengamatan kebulatan hasil proses pemesinan dapat dilakukan dengan cara merubah parameter pemotongan [4].

Standard ISO menganjurkan menggunakan MRZ, karena sesuai dengan makna toleransi. Nilai ketidakbulatan adalah selisih dari radius kedua lingkaran tersebut $(\Delta R)$ dan dinamakan sebagai minimum radial zone (MRZ).

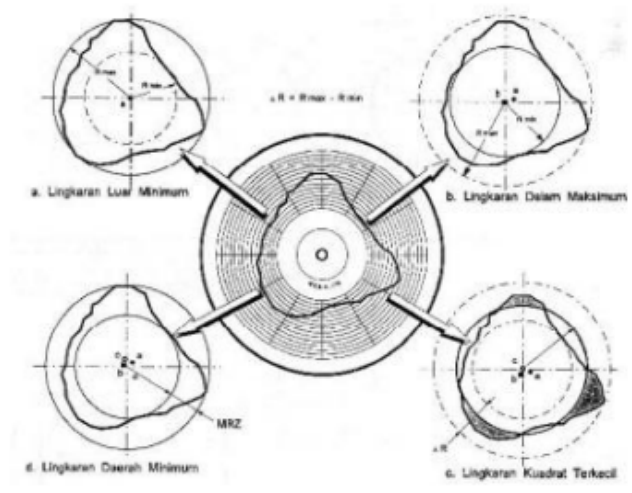

Gambar 1. Grafik polar dari 4 cara pengkuran kebulatan [3]

Pengukuran kebulatan suatu benda dapat dilakukan dengan berbagai macam metoda. Metoda yang pernah dilakukan adalah dengan menggunakan dial indikator, seperti pengukuran kebulatan benda uji hasil proses bubut CNC dan hasil pemotongan mesin bubut manual [5]. Cara penggunaan dial indicator untuk pengukuran kebulatan dapat dilihat pada Gambar 2.

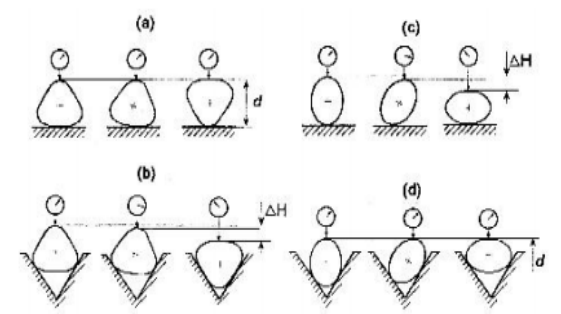

JURNAL MANUTECH Vol. 9, No. 2, Desember 2017: 46-88 
Gambar 2. Pengukuran kebulatan dengan menggunakan dial indikator dan block V

\section{METODE PENELITIAN}

Untuk melaksanakan penelitian ini maka diperlukan langkah-langkah yang sistematis sehingga hasil yang diinginkan dapat tercapai. Langkah-langkah penelitian dapat dilihat pada gambar 3 .

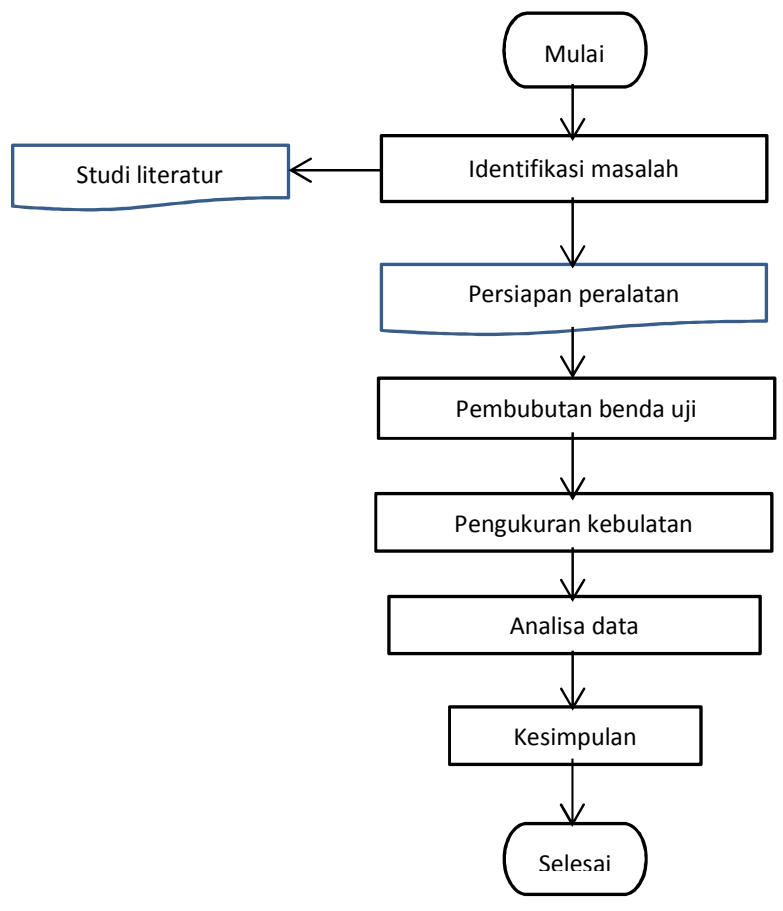

Gambar 3. Diagram flow chart metoda penelitian yang digunakan

Setelah melakukan identifikasi masalah dan melakukan studi literatur dilakukan persiapan peralatan untuk penelitian. Peralatan yang digunakan untuk kegiatan penelitian ini adalah

1. Mesin bubut Doall Lt13

2. Dial indicator dengan ketelitian $0,001 \mathrm{~mm}$

3. Holder pahat dan Tip carbide negatif ISO standard insert dengan radius $0,8 \mathrm{~mm}$

4. Baja diameter $30 \times 200 \mathrm{~mm}$

5. Bench Center + Indicator clam

Proses pembubutan dilakukan dengan cara mencekam benda kerja pada chuck rahang tiga tanpa menggunakan center lihat gambar 4. Ukuran benda uji yang dicekam pada chuck berukuran diameter nominal $30 \mathrm{~mm}$, benda uji tersebut akan dibubut hingga mencapai ukuran diameter nominal $25 \mathrm{~mm}$. Parameter yang digunakan untuk proses pembubutan disesuaikan dengan kondisi mesin yang akan digunakan. Parameter-parameter tersebut yaitu putaran spindle mesin/chuck rahang 3 sebesar $1000 \mathrm{rpm}$, depth of cut sebesar 0,4 mm dan 0,04 mm, feeding yang digunakan sebesar 0.077mm/put.

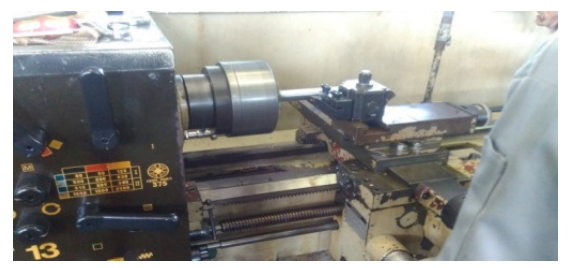

Gambar 4 Pemotongan benda uji di mesin bubut Doall LT 13 
Setelah proses pemotongan benda uji selesai, dilanjutkan dengan pengukuran kebulatan benda uji. Proses pengukuran kebulatan menggunakan alat bantu bench center dan dial indicator. Hasil kebulatan benda uji dianalisa menggunakan metoda lingkaran daerah minimum. Titik dan posisi daerah pengukuran benda uji dapat dilihat pada gambar 5 .

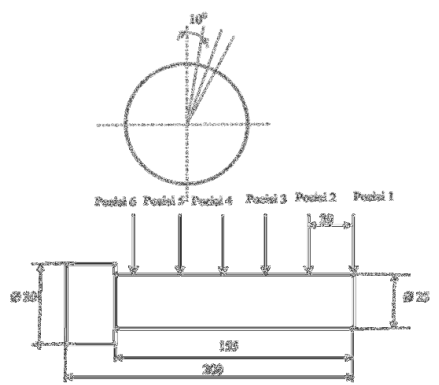

Gambar 5. Posisi pengukuran benda uji hasil bubutan

\section{HASIL DAN PEMBAHASAN}

3.1. Hasil Pengujian Kebulatan

Pengujian kebulatan dilakuan dengan cara memotong benda uji pada masing-masing mesin bubut dan kemudian hasil pemotongan mesin diukur dengan menggunakan alat ukur dial indicator dan bench center gambar 7. Pergerakan benda uji setiap $10^{\circ}$ dilakukan dengan bantuan kertas yang telah digambar berupa bentuk garis yang dibagi menjadi $10^{\circ}$. Kertas tersebut ditempelkan pada bagian ujung benda kerja. Bentuk kertas yang telah gambar berupa bentuk garis dapat dilihat pada gambar 6 . Penyimpangan kebulatan yang terjadi pada benda uji dapat dilihat pada Tabel 1 berikut.

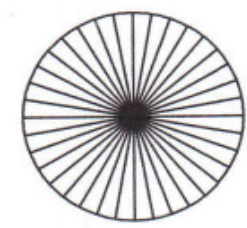

Gambar 6. Garis pembagian untuk pengukuran $10^{\circ}$

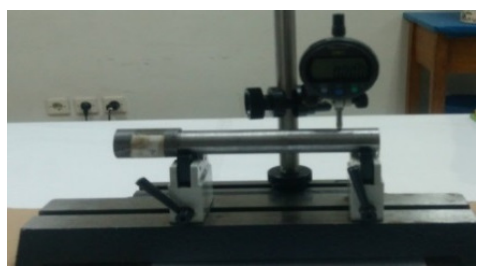

Gambar 7. Proses Pengukuran kebulatan benda uji

Tabel 1. Ketidakbulatan benda uji

\begin{tabular}{|c|c|c|c|c|c|c|}
\hline \multirow{3}{*}{ Posisi } & \multicolumn{6}{|c|}{ No mesin } \\
\hline & Bu 2 & Bu 3 & Bu 5 & Bu 6 & Bu 7 & Bu 8 \\
\hline & \multicolumn{6}{|c|}{ Ketidak bulatan } \\
\hline 1 & 0,051 & 0,046 & 0,073 & 0,042 & 0,057 & 0,082 \\
\hline 2 & 0,036 & 0,026 & 0,046 & 0,036 & 0,03 & 0,067 \\
\hline 3 & 0,024 & 0,02 & 0,035 & 0,031 & 0,021 & 0,053 \\
\hline 4 & 0,021 & 0,012 & 0,027 & 0,029 & 0,028 & 0,043 \\
\hline
\end{tabular}




\begin{tabular}{ccccccc}
\hline 5 & 0,017 & 0,014 & 0,034 & 0,045 & 0,032 & 0,046 \\
\hline 6 & 0,017 & 0,02 & 0,04 & 0,048 & 0,037 & 0,048
\end{tabular}

Merujuk pada tabel 1 tersebut dapat diketahui bahwa nilai ketidak bulatan terbesar terjadi pada benda uji yang dihasilkan oleh mesin bubut 8 dengan nilai sebesar $0,082 \mathrm{~mm}$ pada posisi 1 sedangkan nilai ketidak bulatan terkecil dihasilkan oleh benda uji pada mesin bubut 2 pada posisi 6 dan 5 dengan nilai sebesar $0,017 \mathrm{~mm}$.

\section{SIMPULAN}

Berdasarkan hasil pengujian yang telah dilakukan terhadap mesin bubut doall It 13 yang ada di Politeknik Manufaktur Negeri Bangka Belitung didapat hasil kemampuan mesin bubut untuk memproduksi benda terhadap penyimpangan kebulatan. Penyimpangan kebulatan yang mampu dicapai oleh mesin bubut doall It 13 sebagai berikut $0,082 \mathrm{~mm}$ pada mesin bubut nomor $8,0,073 \mathrm{~mm}$ pada mesin bubut nomor 5, 0,057 $\mathrm{mm}$ pada mesin bubut nomor 7, 0,051 pada mesin bubut nomor 2, 0,048 $\mathrm{mm}$ pada mesin bubut nomor 6 dan $0,046 \mathrm{~mm}$ pada mesin bubut nomor 3 .

\section{DAFTAR PUSTAKA}

[1]. George Schelesinger. (1970). Testing Machine Tools. London: The Machining Publishing Co.

[2]. Erwansyah. (2013). Pengaruh Kecepatan Pemakanan dan Kedalaman Pemotongan terhadap Kekasaran Permukaan dan Kebulatan Hasil Penggerindaan Menggunakan Alat Bantu Khusus(Special Attachment) Penggerindaan di Mesin Bubut. Prosiding Seminar Nasional Teknologi Terapan,Volume 1A.No.1. Oktober 2013.

[3]. Taufic Rochim. (2001). Spesifikasi, Metrologi, dan Kontrol Kualitas Geometrik 1, Bandung, ITB.

[4] Erizal Hamdi,Dodi Sofyan Arief, Adhy Prayitno. (2015). Pengujian Kebulatan Hasil Pembuatan Poros Aluminium Menggunakan Emco T.U CNC -2A SMKN2 Pekanbaru Dengan Roundness Tester Machine. JOM Fteknik, Volume 2 no 2, Oktober 2015.

[5] Muhamad Yanis,(2013), Analisis Profil Kebulatan Untuk Menentukan Kesalahan Geometrik pada pembuatan Komponen Menggunakan Mesin Bubut CNC,ejournal unsri,vol 19, no 1.

[6] DoAll Company.( 1995). Machine Manual. 254,North Laurel Avenue, Des Plaines Illinois $60016 .$. 